\title{
Bilateral lens capsule rupture in a patient with previously undiagnosed Alport's syndrome
}

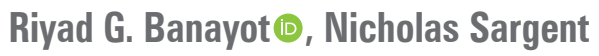 \\ St John Eye Hospital, Jerusalem, Palestine
}

\begin{abstract}
BACKGROUND: The purpose of this paper was to report a case of bilateral lens capsule rupture in a patient with previously undiagnosed Alport's syndrome.

CASE PRESENTATION: A 12-years-old child was referred to our hospital for cataract extraction secondary to decreased visual acuity in the right eye two years after lensectomy and posterior chamber intraocular lens implant in the left eye secondary to assumed traumatic cataract. Slit-lamp examination showed a ruptured anterior capsule in the right eye with lens matter in the anterior chamber. Clinically the patient was anemic and deaf; he was referred for pediatric evaluation and was diagnosed with Alport's syndrome and end-stage renal disease. Once the patient's hypertension was controlled, a lensectomy and posterior chamber intraocular lens implant was performed.

RESULTS: Lensectomy and posterior chamber intraocular lens implant removed the cataract and allowed the restoration of visual acuity.

CONCLUSIONS: Ophthalmologists may be the first to consider the diagnosis of Alport's syndrome based on lens changes. Uncontrolled Blood pressure can delay surgery, during which time intraocular pressure (IOP) should be monitored closely. Results of lensectomies with foldable IOL implantation are successful. To our knowledge, this is the second report of a case of bilateral lens capsule rupture in a patient with previously undiagnosed Alport's syndrome.
\end{abstract}

KEY WORDS: Alport's syndrome; anterior lenticonus; spontaneous capsule rupture

Ophthalmol J 2021; Vol. 6, 57-60

\section{INTRODUCTION}

Alport's syndrome (AS) is an inherited disorder of basement membrane collagen synthesis (type IV). Between $80-85 \%$ result from mutations in gene COL4A5 located on chromosome X (XLAS, $X$-linked inheritance). In about $15 \%$ of cases, mutations occur in COL $4 A 3$ or COL4A4 genes located on non-sex chromosomes (ARAS, autosomal recessive inheritance), where the child inherits two faulty genes. In less than $5 \%$ of cases, the syndrome is inherited as an autosomal dominant (ADAS) pat- tern, where the child inherits a single copy of the faulty COL4A3 or COL4A4 gene. It is characterized clinically by progressive hereditary nephritis, high-tone sensorineural hearing loss, and ocular abnormalities. The prevalence of the disease is one in 50,000 newborns.

Most affected male children present with persistent microscopic haematuria. Hearing and ocular defects appear in late childhood or early adolescence.

Typical ocular manifestations of Alport's syndrome are retinal perimacular flecks, affecting

CORRESPONDING AUTHOR:

Dr. Riyad George Banayot, St. John Eye Hospital, Sheikh Jarrah, P. 0. Box 19960, Jerusalem 91198, Palestine, tel: 00972 (0)2 5828325, fax: 00972 (0)2 5828327; e-mail: Riyadbanayot@gmail.com 
$85 \%$ of males with XLAS, and anterior lenticonus (pathognomonic), which occurs in $25 \%$ of patients with XLAS. Although anterior lenticonus is common, rupture of the anterior capsule is not.

\section{CASE REPORT}

A 12-years-old boy was presented to St. John Eye Hospital with complaints of reduced vision in the left eye lasting for five days. The patient had a history of trauma by his brother using his hand. There was no history of systemic diseases. Slit-lamp examination revealed: normal test results in the right eye and ruptured anterior lens capsule with opaque lens (assumed to be trauma-related) in the left eye. The child was admitted to the hospital. Left lensectomy and posterior chamber intraocular lens (PCIOL) under general anaesthesia was performed the next day. Blood pressure was $100 / 60 \mathrm{~mm} \mathrm{Hg}$ preoperatively. Six weeks follow-up showed: visual acuity $6 / 6$ with -3.00 DS in the right eye and 6/6 with Plano/-0.75 X 45 in the left eye.

Two years later, the same child was referred to our hospital for right cataract surgery. Physical examination revealed that the child was clinically anaemic and had neurosensory deafness (patient produced a report from otolaryngologist showing a history of deafness of 3 years duration). Family history revealed eight healthy older siblings. Ophthalmic examination revealed the right eye had ruptured anterior capsule and cataractous lens (Fig. 1). A paediatric consultation was conducted regarding the patient's general condition. The child was diagnosed with Alport's syndrome and end-stage renal disease. He underwent haemodialysis and blood

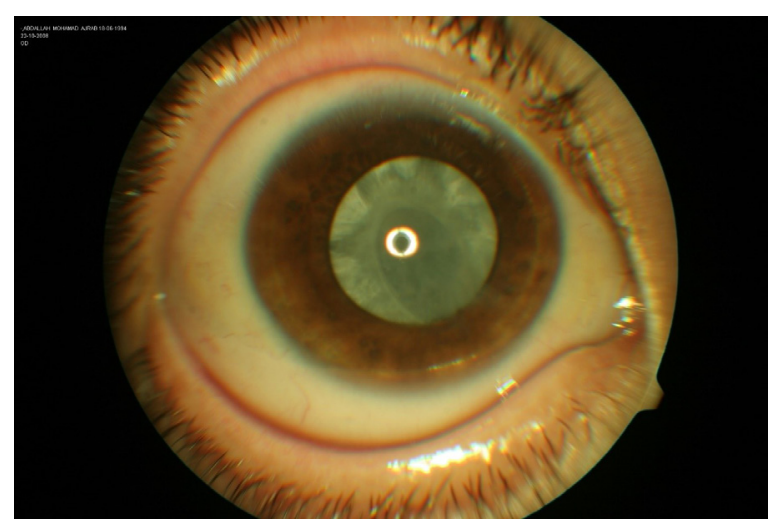

FIGURE 1. Right eye ruptured anterior capsule and cataractous lens transfusions and was started on anti-hypertensive medication (atenolol).

Three months later, the assessment of the right eye cataract extraction was performed. Examination revealed: blood pressure (BP): 240/140 mm $\mathrm{Hg}$, haemoglobin: $10.8 \mathrm{~g} / \mathrm{dL}$, right eye was cataractous with intraocular pressure (IOP) of $30 \mathrm{~mm} \mathrm{Hg}$. Surgery was postponed due to poorly controlled systemic hypertension (despite being on atenolol and hemodialysis three times/week). The patient was started on timolol and dorzolamide drops and was referred urgently to his physician, who added nifedipine systemically.

The child was re-admitted to our hospital three weeks later for surgery, but the right eye IOP was $48 \mathrm{~mm} \mathrm{Hg}$, and his BP was 190/125 mm Hg. Oral acetazolamide (Diamox) was added to his medication regimen. Three days later, right eye IOP was $23 \mathrm{~mm} \mathrm{Hg}$, and BP was 166/113 mm Hg. The child underwent a right lensectomy with foldable PCIOL under general anesthesia.

Five weeks post-operatively, examination revealed: visual acuity $6 / 6$ with -3.00 DS in the right eye and 6/6 with $-2.75 /-1.00 \times 110$ in the left eye (Fig. 2). Fundus examination of the right eye showed perimacular exudates/flecks (Fig. 3).

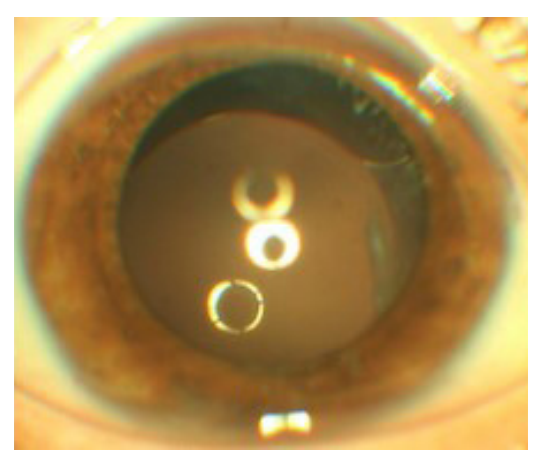

FIGURE 2. Right eye -2 weeks post-operative

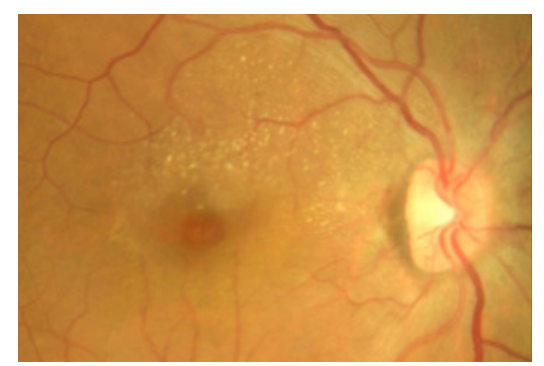

FIGURE 3. Right ye - perimacular exudates: flecks two weeks post-operative 


\section{DISCUSSION}

Dr. Cecil Alport, in 1927 was the first to identify an association between nephritis and deafness [1]. Arnott et al. [2] in 1966 reported anterior lenticonus as a specific sign of Alport's syndrome. Nielsen in 1978 stated that reported cases of anterior lenticonus were only described in patients with Alport's syndrome [3].

Anterior lenticonus may not be distinguished at birth but develops progressively over the years. The average age for lenticonus diagnosis is the second decade. The condition is bilateral, where the anterior surface of the lens protrudes centrally, causing high myopia. Vision deteriorates gradually over the years and, and there is no noticeable improvement of visual acuity with optical correction.

Perimacular flecks do not hinder vision and are linked to renal deterioration. Flecks and pigment epithelial lesions are identified with Alport's syndrome.

With slit-lamp examination, the lenticonus is seen as a transparent, local, tapering bulge of the lens capsule and cortex, located axially. Lenticonus is seen with retro-illumination as an 'oil droplet' shape in its early stages. Swan and Patel [4] emphasized that anterior lenticonus may be difficult to observe with the slit-lamp. However, an altered retinoscopic reflex should alert the practitioner to look more closely at the ocular media.

Ruotsalainen and Tarkanan [5] reported mean thickness values of $8.2 \pm 3.2 \mu \mathrm{m}$ for the central anterior capsule. Ohkubo et al. [6] reported a $3 \mu \mathrm{m}$ thickness for the central portion of the anterior capsule of a patient with Alport's syndrome (controls had a thickness of $20 \mu \mathrm{m}$ ). Factors that eventually cause the capsule to rupture include histological changes of the anterior capsule, stressed structures during accommodation, and anterior lens curvature becoming more convex centrally.

The diagnosis of Alport's syndrome is suspected with the following findings: persistent glomerular hematuria, positive family history for Alport's syndrome or renal failure, or characteristic clinical features (progressive neurosensory deafness, lenticonus, or retinopathy), or glomerular basement membrane (GBM) with an abnormal collagen IV. Diagnosis is confirmed by using kidney biopsy (lamellated GBM) or genetic testing (mutations in COL4A5 or COL4A3 or COL4A4).

A literature review showed few anterior lens capsule/lenticonus rupture cases associated with Alport's syndrome [7-10].
Our case represents a spontaneous rupture in a patient not known to have anterior lenticonus. With a history of trauma and the lack of findings in the unaffected eye, clinically significant anterior lenticonus was most likely not present in the traumatized eye. However, a sub-clinical abnormality of the anterior capsule must have been present to allow the anterior capsule to rupture secondary to a traumatic event that was not severe enough to affect the rest of the anterior segment. We suspect an early stage of Alport's syndrome was present.

The majority of males with Alport's syndrome have hematuria and high tone hearing loss by the age of 10 years. The progression of renal failure varies among patients. Many males develop failure in their teens, but some do not develop it until the fourth decade of life.

We report a case of bilateral anterior lens capsule rupture in a child who was not previously diagnosed with Alport's syndrome. A search of the literature revealed one case similar to ours [11].

Our patient did not show any typical signs of renal failure or hearing loss on his first presentation, and the attending physician assumed his condition to be trauma-related. When the patient presented to the hospital two years later, he had been diagnosed with neurosensory deafness but not nephropathy.

Limitations of the study include the lack of regular follow-up, and lack of genetic testing.

Early diagnosis may prevent amblyopia, cataract, and strabismus. Also, optical devices can correct lenticular myopia, and hearing aids can reduce sensory neural hearing loss. In our case, the ophthalmologist was the first physician to evaluate the patient before serious systemic complications occurred.

\section{CONCLUSIONS}

Ophthalmologists may be the first to consider the diagnosis of Alport's syndrome based on lens changes. Uncontrolled blood pressure can delay surgery, during which time IOP should be monitored closely. Results of lensectomies with foldable IOL implantation are successful.

\section{Acknowledgments \\ NIL.}

\section{Competing interests}

NIL. 


\section{REFERENCES}

1. Hurst AF. Hereditary familial congenital hemorrhagic nephritis. BMJ. 1927; 1(3454): 504-506, doi: 10.1136/bmj.1.3454.504, indexed in Pubmed: 20773074.

2. Arnott EJ, Crawfurd MD, Toghill PJ. Anterior lenticonus and Alport's syndrome. Br J Ophthalmol. 1966; 50(7): 390-403, doi: 10.1136/ bjo.50.7.390, indexed in Pubmed: 5947587.

3. Nielsen CE. Lenticonus anterior and Alport's syndrome. Acta Ophthalmol (Copenh). 1978; 56(4): 518-530, doi: 10.1111/j.1755-3768.1978. tb01365.x, indexed in Pubmed: 735766.

4. Swann PG, Patel S. Lenticular changes in Alport's syndrome. Clin Exp Optom. 2005; 88(1): 53-54, doi: 10.1111/j.1444-0938.2005. tb06664.x, indexed in Pubmed: 15658927.

5. Ruotsalainen J, Tarkkanen A. Capsule thickness of cataractous lenses with and without exfoliation syndrome. Acta Ophthalmol (Copenh). 1987; 65(4): 444-449, doi: 10.1111/j.1755-3768.1987.tb07021.x, indexed in Pubmed: 3661144.

6. Ohkubo S, Takeda H, Higashide T, et al. Immunohistochemical and molecular genetic evidence for type IV collagen alpha5 chain abnormality in the anterior lenticonus associated with Alport syndrome. Arch Ophthalmol. 2003; 121(6): 846-850, doi: 10.1001/archopht.121.6.846, indexed in Pubmed: 12796257.
7. Olitsky SE, Waz WR, Wilson ME. Rupture of the anterior lens capsule in Alport syndrome. J AAPOS. 1999; 3(6): 381-382, doi: 10.1016/ s1091-8531(99)70051-0, indexed in Pubmed: 10613586.

8. Gupta A, Ramesh Babu K, Srinivasan R, et al. Clear lens extraction in Alport syndrome with combined anterior and posterior lenticonus or ruptured anterior lens capsule. J Cataract Refract Surg. 2011; 37(11): 2075-2078, doi: 10.1016/j.jcrs.2011.09.005, indexed in Pubmed: 22018369.

9. Agrawal N, Nayak DP, Haripriya A, et al. Phacoemulsification with toric IOL implantation in Alport syndrome with anterior lenticonus having spontaneously ruptured anterior capsule. Eur $\mathrm{J}$ Ophthalmol. 2015; 25(5): e78-e80, doi: 10.5301/ej0.5000579, indexed in Pubmed: 25743777.

10. Boss JD, McDermott M. Capsulorhexis tearing pattern during phacoemulsification in anterior lenticonus due to Alport syndrome. Eur J Ophthalmol. 2016; 26(3): e39-e41, doi: 10.5301/ejo.5000720, indexed in Pubmed: 26692055.

11. van der Westhuizen DP, Stuart KV. Bilateral spontaneous anterior lens capsule ruptures in a child: A rare presentation of Alport syndrome. Am J Ophthalmol Case Rep. 2020; 20: 100896, doi: 10.1016/j. ajoc.2020.100896, indexed in Pubmed: 33015404. 